\title{
The Government's Environment Policy Index Impact on Recycler Behavior in Electronic Products Closed-Loop Supply Chain
}

\author{
Suchao He, ${ }^{1}$ Xigang Yuan, ${ }^{2}$ and Xiaoqing Zhang ${ }^{2}$ \\ ${ }^{1}$ The School of Business Administration, Southwestern University of Finance and Economics, Chengdu 611130, China \\ ${ }^{2}$ The School of Statistics, Southwestern University of Finance and Economics, Chengdu 611130, China \\ Correspondence should be addressed to Suchao He; hsciswufe@163.com
}

Received 28 December 2015; Revised 23 January 2016; Accepted 28 January 2016

Academic Editor: Paolo Renna

Copyright (C) 2016 Suchao He et al. This is an open access article distributed under the Creative Commons Attribution License, which permits unrestricted use, distribution, and reproduction in any medium, provided the original work is properly cited.

We establish the model of multilevel closed-loop supply chain (CLSC) which included raw material supplier, manufacturer, distributor, retailer, and third-party recycler based on system dynamics (SD). Considering factors which influence recycler behavior-environmental policy index and recovery delay, we apply SD software-Vensim-to simulate CLSC model and study recycler behavior's influence on the entire CLSC through calculating the bullwhip effect of all levels members order rate. Research shows that (1) the larger the environmental policy index, the greater the recycle proportion and the better the effect of weakening retailer's order rate in forward supply chain, which however, increasingly, strengthen the reverse supply chain bullwhip effect, (2) the shorter the recovery delay, the better the effect of weakening the forward supply chain bullwhip effect and the longer the recovery delay, which increasingly weakens the reverse supply chain bullwhip effect, and (3) the effect of environmental policy index on the bullwhip effect of all levels members order rate is more significant than recovery delay.

\section{Instruction}

Nowadays, closed-loop supply chain has become a new research point since people pursue circular economy and social sustainable development. Closed-loop supply chain is a new supply chain form in circular economy. Van Wassnhove et al. [1] and Jayaraman et al. [2] thought that we can build a complete closed-loop supply chain which includes supply, manufacturing, retail, and recycling and adds to products (parts) recycler.

With products (parts) that recycler is adding to the supply chain, the structure of supply chain gradually changes. Domestic and foreign scholars deeply discuss cooperation mechanism between various members in the supply chain. Savaskan et al. [3] researched the cooperation mechanism problem between manufacturers and retailers, with the recycler participating in the supply chain. Forrester [4], Sterman [5], and Baik [6] mainly discussed the cooperative and competitive factors in the supply chain and come up with the corresponding cooperation strategy. Then, Liu et al.
[7] considered competitive factors in different supply chain and established appropriate cooperation model and propose effective solving measure.

In early years, many scholars would like to discuss the bullwhip effect in open-loop supply chain. They research this problem from the following aspects. One aspect is that they discuss the bullwhip effect using different forecasting method. For example, Chen et al. $[8,9]$ demonstrated that the use of an exponential smoothing forecasting method by the retailer can cause the bullwhip effect and contrasted these results with the increase in variability due to the use of a moving average forecasting method. Kim and Ryan [10] pointed out that forecasting method can cause the bullwhip effect. Gaalman and Disney [11] revealed that bullwhip is fundamentally caused by the covariance between the inventory level and the demand forecasting method.

The other aspect is that they discuss the bullwhip effect using different ways of sharing demand information. For example, Chen et al. $[8,9]$ centralized customer demand information and demonstrated that the bullwhip effect can 
be reduced, but not completely eliminated by centralizing demand information. Chatfield et al. [12] pointed out that information sharing and information quality are highly significant to reduce the bullwhip. Hosoda and Disney [13] analyzed the level of the supply chain with no impact on the bullwhip effect; bullwhip is determined by the accumulated lead-time from the customer and the local replenishment lead-time.

With the third-party recycler taking part in the supply chain, the open-loop supply chain becomes the closed-loop supply chain. In recent years, more scholars are interested in discussing the bullwhip effect in closed-loop supply chain using system dynamics method. For example, Cannella and Ciancimino [14] pointed out that supply chain collaboration mitigates the bullwhip effect, provides inventory stability, limits lumpy orders, and enhances customer service level. Lehr et al. [15] developed a model that allows an original equipment manufacturer in the electronics industry to test different value recovery strategies for business-to-business products in a closed-loop supply chain setting. They analyze the complexity of reverse logistics processes using the system dynamics model. Savaskan et al. [16] pointed out that the bullwhip in the closed-loop supply chain is bigger than one in traditional supply chain by using a simple system dynamic model.

As is known to us, some works would like to discuss the bullwhip effect in the closed-loop supply chain. At the same time, when the third-party recycler adds to the closed-loop supply chain, more and more scholars would like to research the third-party recycler impact on the bullwhip effect in closed-loop supply chain. For example, Ferrer and Swaminathan [17] studied a firm that made new products in the first period and used returned cores to make remanufactured products (along with new products) in future periods. Georgiadis and Besiou [18] investigated the significance of the factors that comprised the environmental sustainability strategies (environmental legislation and green image) and the operational features of the closed-loop supply chain (CLSC). Rogers et al. [19] pointed out that secondary market can provide a place for unwanted items to be bought and sold, reducing the products' ecological impact and creating economic value. Wei and Zhao [20] come up with the pricing decision problem of a fuzzy closed-loop supply chain with retail competition. Das and Dutta [21] developed a simulation model based on system dynamics to analyze the long-term behavior of a multi-forward-reverse supply chain with fuzzy demand.

As can be seen from the above articles, the shortage of normal research is as follows: Firstly, most scholars research the supply chain coordination problem when the recyclers can be joined in closed-loop supply chain. Few scholars research third-party recycler behavior impact on the whole members in the closed-loop supply chain. Secondly, fewer scholars research the environment policy index impact on recycler behavior in electronic products closed-loop supply chain. As a result, we establish the model of the multilevel closed-loop supply chain (CLSC) which includes a raw material supplier, a manufacturer, a distributor, a retailer, and a third-party recycler based on system dynamics (SD). We simulate CLSC model and analyze that the environmental policy index impacts on the third-party recycler behavior. What is more, we discuss that the policy impacts on the bullwhip effect in the electronic products closed-loop supply chain.

The rest of this paper is organized as follows: in Section 2, electronic products closed-loop supply chain dynamics model is built. In Section 3, there are parameter definition and equations. Section 4 provides electronic products recyclers' behavior in electronic products closed-loop supply chain system dynamics simulation. Conclusion is given in Section 5.

\section{Electronic Products Closed-Loop Supply Chain Dynamics Model}

In this section, we use Vensim software to establish electronic products closed-loop supply chain model, which includes raw material supplier, manufacturer, distributor, retailer, and third-party recycler. At the beginning of the model, the raw material supplier offer raw material, the manufacturer produces the electronic products, and then the retailer can sell the electronic products and it can be sent to the costumer. At last, the electronic products recycler can recycle the old electronic products. Electronic products manufacturer is remanufacturing the old electronic products and it can once again go into the forward electronic products supply chain.

Based on the above analysis, the conception model of electronic products closed-loop supply chain is shown in Figure 1; the system dynamics simulation model is shown in Figure 2. In this mode, the inventory of each supplier is decide by their respective delay time of raw material productivity, returned old electronic products remanufacturing rate, and raw material delivery rate. The manufacturer's inventory depends on raw material supplier's delivery rate, electronic products manufacturer's recycling old electronic products remanufacturing rate, electronic products delay time, and the rate of the distribution to electronic products retailer. Electronic products retailer's inventory is determined by the market sales and their transport delay, respectively. Electronic products retailers order rate, electronic products manufacturer produce demand rate, and the requirements of the supplier's raw material rate are all determined by the market sales and inventory adjustment.

\section{Parameter Definition and Equations}

\subsection{Model Assumption}

Assumption 1. Retail sales equal the market demand. Low retail sales show lower market demand; otherwise it shows higher demand.

Assumption 2. Electronic products manufacturer's manufacturing capacity, remanufacturing capacity, electronic products retailer's sales ability, and recycler's recovery ability have no limit. 


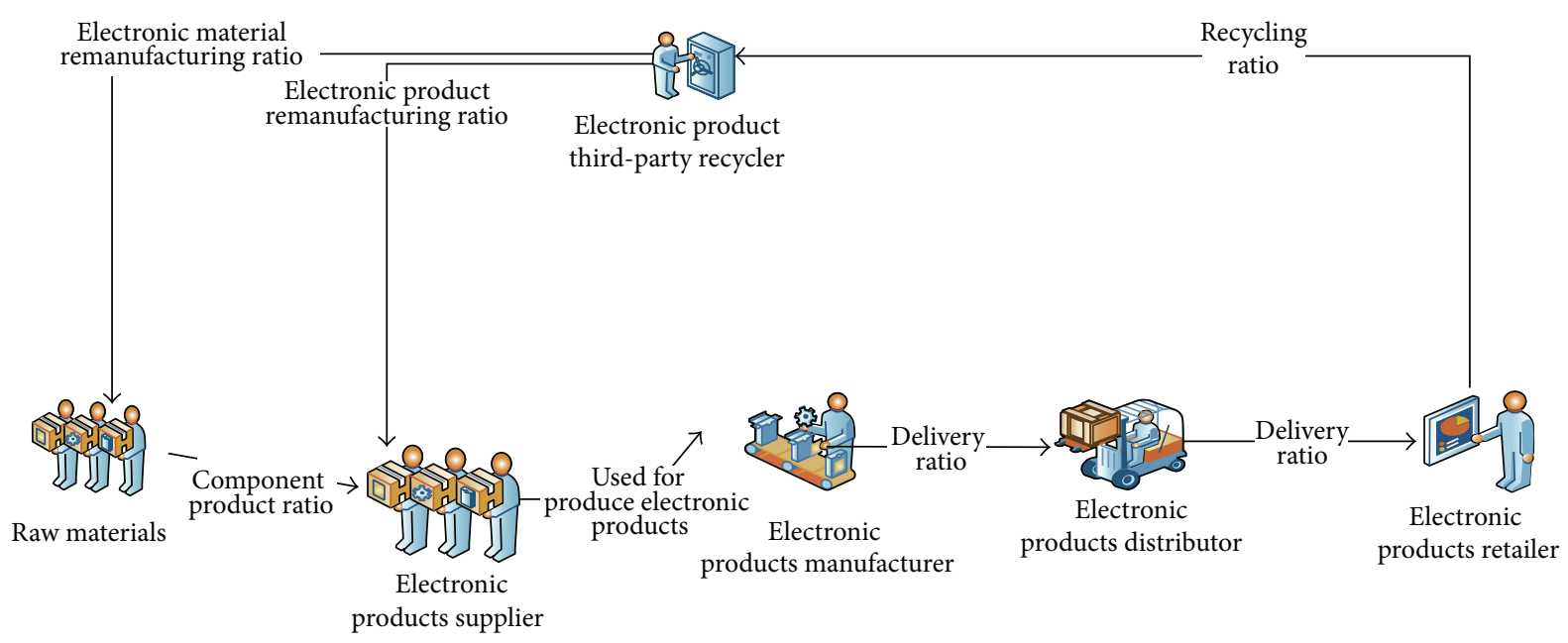

FIGURE 1: The conception model of electronic products closed-loop supply chain.

Assumption 3. Each company has safety stock inventory in electronic products closed-loop supply chain, so that it can better meet the need of each company.

3.2. Parameter Setting. Based on above analysis, we set the relevant constant value (Table 1).

\subsection{Equation Instructions}

3.3.1. The Equation of Electronic Products Supplier. Consider the following:

(1) Supplier inventory = DELAY1 (parts productivity, delivery delay of the supplier's, and supplier production delays time) + recycled raw material remanufacturing rate - delivery rate from supplier to manufacturer.

(2) Supplier production demand rate $=\operatorname{MAX}(0$, supplier's sale forecast + supplier's expect inventory/inventory adjustment time - supplier inventory/inventory adjustment time).

(3) Supplier's sale forecast $=$ SMOOTH (delivery rate from supplier to manufacturer, average moving period time).

(4) Delivery rate from supplier to manufacturer = DELAY1 (manufacturer production order, delivery delay of the supplier's).

(5) Supplier production orders $=$ supplier production demand rate - recycled raw material remanufacturing rate.

(6) Supplier's expect inventory $=$ supplier's sale forecast $*$ the sustainable time of expect inventory.

(7) Raw material productivity $=$ supplier production orders.

3.3.2. The Equation of Electronic Products Manufacturer. Consider the following:

(8) Manufacturer inventory $=$ DELAY1 (delivery rate from supplier to manufacturer, manufacturer
TABLE 1: The constant value.

\begin{tabular}{lc}
\hline Parameters & Time \\
\hline Dynamics weeks & 600 weeks \\
Component produce capacities & 800 units/week \\
Material produce delay & 1 week \\
Produce time of the Electronic products & 1.5 weeks \\
Delay time & 40 week \\
Electronic retailer order delay & 1 week \\
The delivery delay & 1.5 weeks \\
Order delay of electronic products distributor & 1 week \\
Recycling delay of the third-party recycler & 1 week \\
Safety inventory of the third-party recycler & 60000 \\
Sustainable time of the electronic products & 1.5 weeks \\
manufacturer's inventory & \\
Electronic products retailer inventory adjustment & 2 weeks \\
time & \\
Remanufacturing proportion of electronic & $50 \%$ \\
products & 1.5 weeks \\
Component production time & 1.5 weeks \\
Sustainable time of component inventory & 850 units/week \\
The capacity of electronic product & 1 week \\
Moving average period & 2 weeks \\
Adjustment time of component inventory & 1 week \\
Produce delays & 1 week \\
Transportation delay & 300 weeks \\
The lifetime of the electronic products & 1 week \\
The adjustment time of the third-party recycler & 1 week \\
Electronic products remanufacturing delay & 2 weeks \\
Inventory adjustment time of electronic products & \\
manufacturers & 2 weeks \\
Adjustment time of electronic distributor & \\
inventory &
\end{tabular}

production delays time, and delivery delay of the supplier's) + recycled production remanufacturing rate - delivery rate from manufacturer to retailer. 


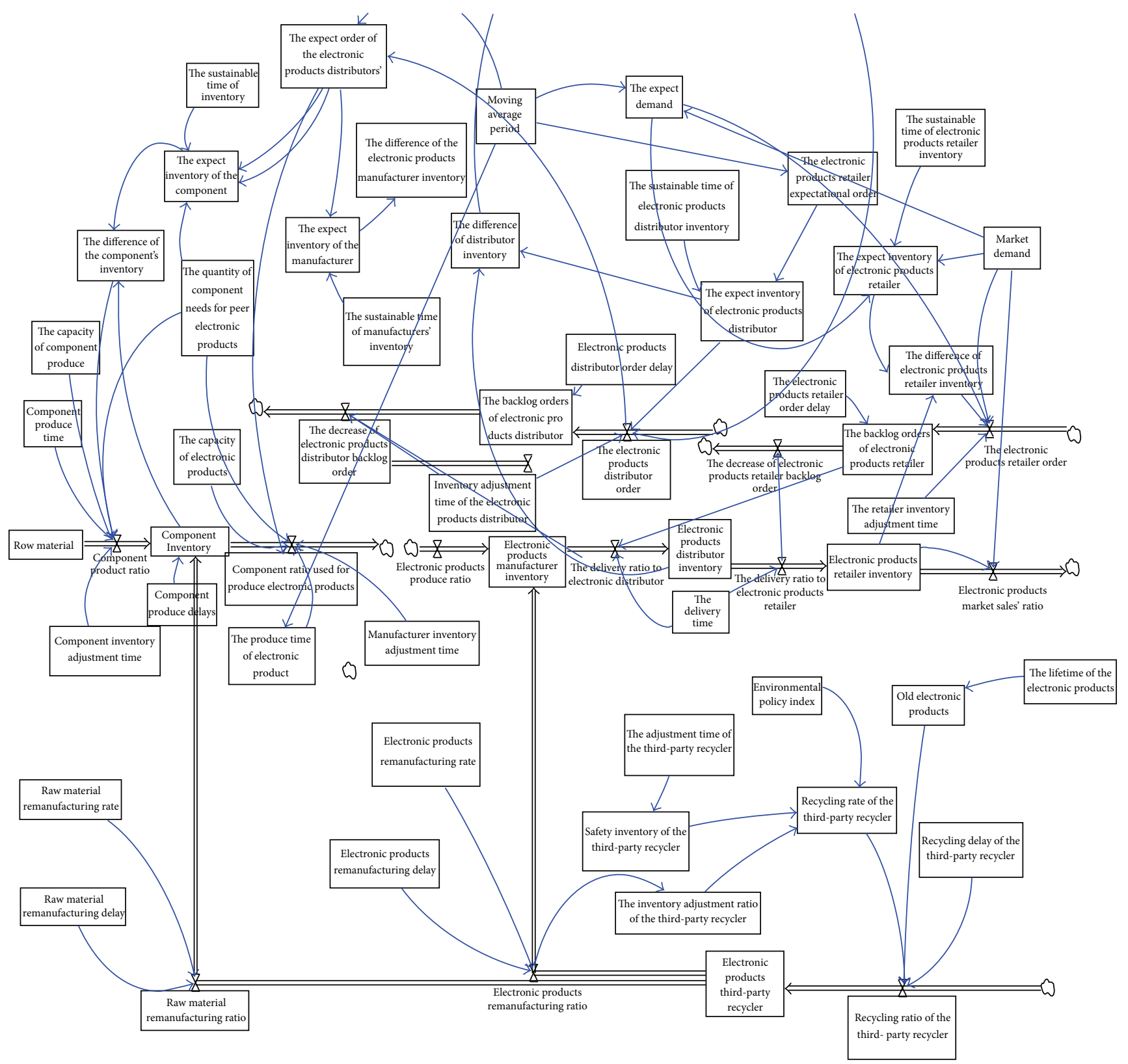

FIGURE 2: The electronic products closed-loop supply chain dynamic flow diagram.

(9) Manufacturer production order $=\operatorname{MAX}(0$, manufacturer production demand rate - recycled production remanufacturing rate).

(10) Manufacturer production demand rate $=\operatorname{MAX}(0$, manufacturer sale forecast + manufacturer expect inventory/inventory adjustment time - manufacturer inventory/inventory adjustment time).

(11) Manufacturer expect inventory = inventory adjustment time $*$ manufacturer sale forecast.

(12) Manufacturer's sale forecast $=$ SMOOTH (delivery rate from manufacturer to retailer, average moving period time).
3.3.3. The Equation of Electronic Products Retailer. Consider the following:

(13) Retailer inventory = DELAY1 (delivery rate from manufacturer to retailer, transportation delay) retailer market sale's rate.

(14) Delivery rate from manufacturer to retailer = DELAY1 (retailer purchase order, delivery delay of the manufacturer).

(15) Retailer expect inventory $=$ retailer's sale forecast $*$ the sustainable time of expect inventory. 
(16) Retailer purchase order $=\operatorname{MAX}$ (0, retailer's sale forecast + retailer expect inventory/inventory adjustment time - retailer inventory/inventory adjustment time).

(17) Retailer's sale forecast $=$ SMOOTH (retailer market sale's rate, average moving period time).

\subsubsection{The Equation of Electronic Products Recycler. Consider} the following:

(18) Recycled product inventory = DELAY3 (recycled delay, recycled product rate $*$ recycled production adjustment time) - recycled production remanufactured rate - recycled parts remanufactured rate.

(19) Recycled production remanufactured rate $=$ DELAY3 (recycled product inventory $*$ recycling production remanufactured ratio/recycled production adjustment time, recycled production remanufactured delay).

(20) Recycled product rate $=$ DELAY1I (recycled product ratio $*$ retailer 1 market sale's rate, recycled product ratio $*$ retailer 2 market sale's rate, recycled delay).

(21) Recycled production remanufactured rate $=$ DELAY3 (recycled product inventory $*$ recycling production remanufactured ratio/recycled production adjustment time, recycled production remanufactured delay).

(22) Recycled parts remanufactured rate = DELAY3 (recycled product inventory $*$ recycling parts remanufactured ratio/recycled production adjustment time, recycling parts remanufacturing delay).

(23) Recycling ratio $=$ environmental policy index $*$ (benchmark recycling ratio $+\delta *$ remanufacturing order rate).

(24) The market demand = the maximum market demand $-\lambda *$ unit price + the market random demand. The maximum market demand $=10000000$; unit price $=$ random uniform $(500,800,0)$; the market random demand $=$ random uniform $(-500,1000,500)$; we set that $\lambda=3$, so the market demand $=$ the maximum market demand $-3 *$ unit price + the market random demand.

\section{Electronic Products Third-Party Recyclers Behavior in Closed-Loop Supply Chain Dynamics Simulation}

Recyclers by providing the used remanufacturing product can be formed reverse supply chain. The old electronic product is delay function of retailer's sales ratio. Recycling ratio is the delay function of the old electronic products and recycling rate. Therefore, the third-party recycler's recycling behavior is mainly affected by recycling rate and recycling delay.

From 2009, we publish "the circular economy promotion law"; after that, in the year 2011, we also publish "the regulation of waste electric products recycling." From this aspect, the government pays much more attention on the resource recycling and environmental protection. In above two laws, "producer responsibility" has been put forward. It requires that the firm should be responsible for protecting the environment in the process of production; what is more, the firm should protect the environment in the whole lifetime. The government's environmental policy can impact on the manufacturer's choice. Based on above analysis, the government's environmental policy can influence the behavior of the firm, we can measure this phenomenon by using "environmental policy index," which can be understand as the environmental policy can promote recycler increasing the recycling ratio.

In the electronic products closed-loop supply chain system, the recycling ratio is determined by the recycling rate. Firstly, we assume that the recycler can recycle the old electronic products at a certain benchmark, the electronic products manufacturer remanufacturing the electronic products. According to the remanufacturing ratio, the third-party recycler predicts the remanufacturing ratio in the next stage. What is more, we can get that remanufacturing order rate is higher; the third-party recycler's recycling ratio is higher. Based on above analysis, for the third-party recycler's recycling ratio calculation, we introduce environmental policy index; we would like to point out that environmental policy can promote recycler increase recycling ratio.

4.1. The Third-Party Recycler's Behavior Analysis under the Environmental Policy Index. We set that INITIAL TIME $=0$ Week, FINAL TIME $=600$ Week, TIME STEP $=1$ Week, and SAVEPER = TIME STEP.

In the dynamic process, we set recycling ratio $=0.3$; the recycling delay $=9$ week, the environmental policy index is equal to 1,3 , and 5 . We should explain that the environmental policy index $=1$ means that environmental policy has no effect on recycling ratio; the environmental policy index $=3$ means that environmental policy prompt the recycling ratio is 3 times of the original recycling ratio; the environmental policy index $=5$ means that environmental policy prompt the recycling ratio is 5 times of the original recycling ratio.

When the environmental policy index $=3$, we set that the recycling delay $=2$ weeks, 6 weeks, and 12 weeks, so that we can study recycler's recycling dynamics behavior in these three conditions.

4.1.1. The Recycling Ratio under Different Environmental Policy Index. From Figure 3, we can see that the environmental policy index becomes more increasing and the third-party recycler recycling ratio becomes more increasing. What is more, the third-party recycler recycling ratio has some float. The reason is that the remanufacturing ratio in manufacturer at each time is fluctuation.

4.1.2. The Order Demand of All the Members under Environmental Policy Index. From Figures 4, 5, and 6, we can see that, with the environmental policy index increasing, the fluctuation of the row material supplier production demand 
TABLE 2: The bullwhip effect in all members under different environmental policy index.

\begin{tabular}{lccc}
\hline & \multicolumn{2}{c}{ The bullwhip effect } \\
& Environmental policy index $=1$ & Environmental policy index $=2$ & Environmental policy index $=3$ \\
\hline RS demand rate & 110.34 & 98.35 & 90.36 \\
EM production order & 94.87 & 85.35 & 70.24 \\
ER purchase order & 82.59 & 78.52 & 60.35 \\
\hline
\end{tabular}

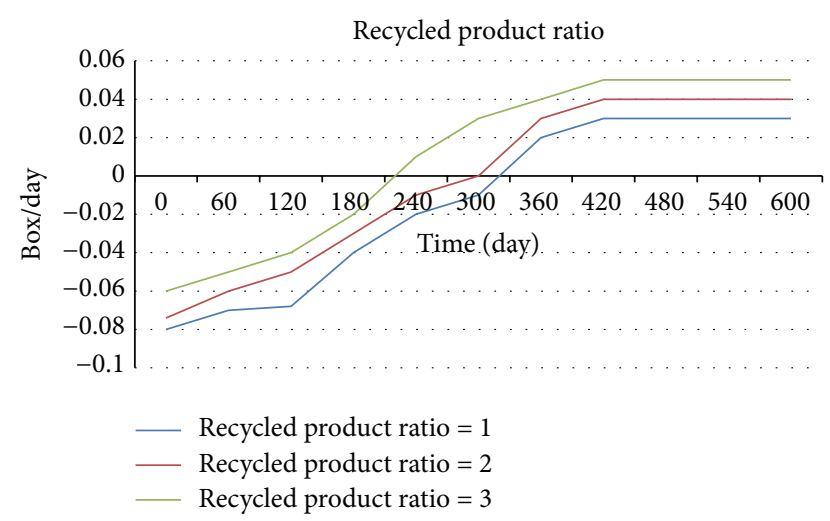

FIGURE 3: The third-party recycler's recycling ratio under different environmental policy index.

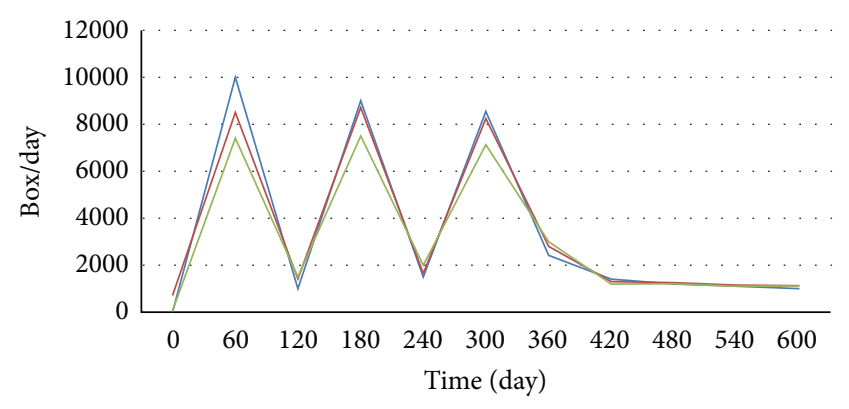

_ Raw material supplier production demand rate
_ Electronic products manufacturer produce order
Electronic products retailer purchase order

FIGURE 4: The environmental policy index $=1$, the order demand fluctuations in various members.

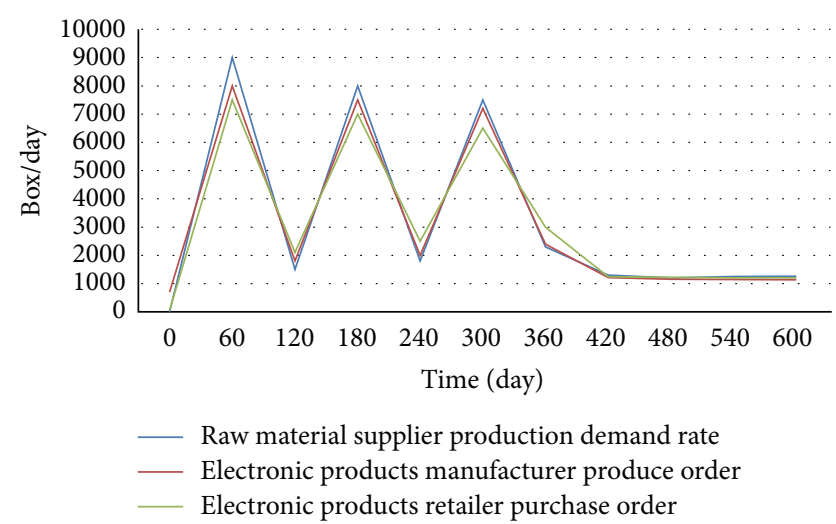

FIGURE 5: The environmental policy index $=2$, the order demand fluctuations in various members.

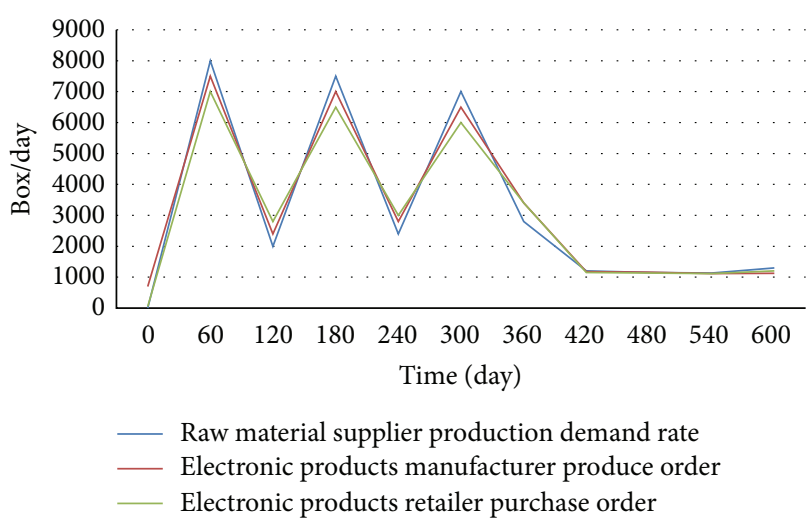

FIGURE 6: The environmental policy index $=3$, the order demand fluctuations in various members.

rate, the fluctuation of the electronic products manufacturer production order, and the fluctuation of the electronic products retailer purchase order becomes are decreasing. The reason is that the recycling ratio in the third-party recycler can increase as the environmental policy index increases. The quantity of the order in the firm of the supply chain can decrease and the fluctuation of the order can decrease. In other words, the firm in the forward supply chain can predict the market demand more accuracy.

Under different environmental policy index, the thirdparty recycler's behavior can cause the order demand fluctuation in all members of the closed-loop supply chain. In this paper, we use the bullwhip effect to understand the dynamics characteristics for the third-party recycler. The bullwhip effect in all members under different environmental policy is index in Table 2.

From Table 2, we can get the following conclusions: (1) the forward supply chain and the reverse supply chain produce the obvious bullwhip effect; (2) the greater the thirdparty recycler's recycling ratio, the better the bullwhip effect in the electronic products retailer's.

4.2. The Third-Party Recycler's Behavior Dynamics Analysis under Recovery Delay. We set that INITIAL TIME $=0$ Week, FINAL TIME $=600$ Week, TIME STEP $=1$ Week, and SAVEPER = TIME STEP.

4.2.1. The Third-Party Recycler's Recycling Ratio in Different Recycling Delay. From Figure 7, we can see that, with the change of recycling delay, the recycling ratio can produce different volatility; this mainly has relationship with electronic products manufacturer's order rate. As is known to us, 
TABLE 3: The bullwhip effect in all members with different recycling delay.

\begin{tabular}{lccc}
\hline & \multicolumn{2}{c}{ The bullwhip effect } & \\
& Recycling delay $=3$ & Recycling delay $=6$ & Recycling delay =9 \\
\hline RS demand rate & 89.14 & 80.35 & 78.36 \\
EM production order & 79.87 & 70.35 & 65.44 \\
ER purchase order & 70.59 & 67.52 & 60.89 \\
\hline
\end{tabular}

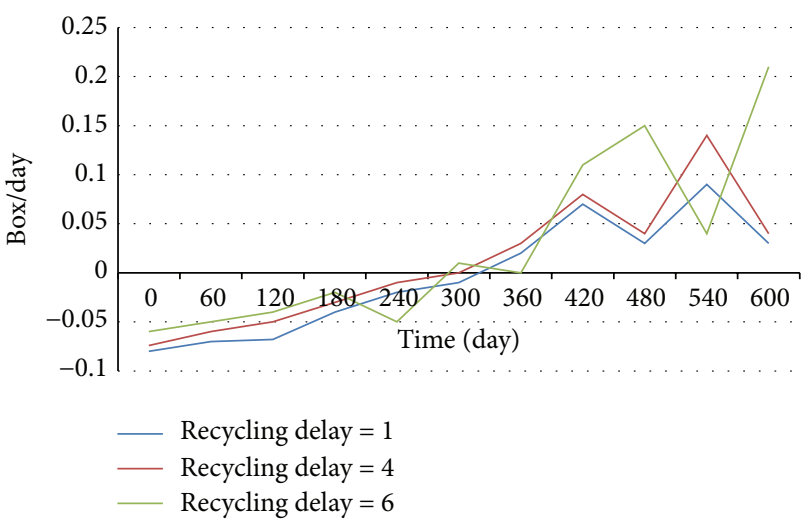

FIGURE 7: The third-party recycler's recycling ratio in different recycling delay.

the longer the recycling delay, the larger the recycling ratio in the third-party recycler. As a result, this can impact the fluctuation of the remanufacturing ratio and the fluctuation of the demand.

4.2.2. The Bullwhip Effect in All Members with Different Recycling Delay. Under different recycling delay, the thirdparty recycler's behavior can cause the fluctuation order demand of all members. We can use bullwhip effect under different recycling delay, to understand the third-party recycler's dynamics characteristics.

From Table 3, we can get the following conclusion: with the recycling delay increasing, the bullwhip effect in electronic products manufacturer and the electronic products retailers' can become more strengthened in the forward supply chain. On the contrary, the bullwhip effect in the reverse supply chain can be weakened.

\section{Conclusion}

We find that recycler's behaviors have impact on the electronic products closed-loop supply chain, and we can draw the following conclusions: (1) with the environmental policy index increasing, the fluctuation of the raw material supplier production demand rate, electronic products manufacturer production order, electronic products retailer purchase order become decreasing; (2) the forward supply chain and the reverse supply chain produce the obvious bullwhip effect; (3) the greater the third-party recycler's recycling ratio, the better the bullwhip effect in the electronic products retailer's; (4) with the recycling delay increasing, the bullwhip effect in electronic products manufacturer and the electronic products retailers' can become more strengthened in the forward supply chain.

From our study, we found that the government's environmental policy has deep impact on the behavior of the electronic products recycler. Therefore, the electronic firm should manage the forward supply chain; at the same time, the firm should pay more attention to manage the reverse supply chain. The bullwhip effect in electronic products closed-loop supply chain can reduce as the recycling ratio increases. It can promote the electronic products firm to pay more attention to the products recovery and reuse. It can reduce the cost and improve the efficiency, so that it can realize the sustainable development of the society.

\section{Conflict of Interests}

The authors declare that there is no conflict of interests regarding the publication of this paper.

\section{Acknowledgment}

This research is supported by the Fundamental Research Funds for the Central Universities (JBK1507049 and JBK 1507100).

\section{References}

[1] L. N. Van Wassnhove, H. R. Krikke, and J. Q. Bloemhof-Ruwaard, "Design of closed-loop supply chains: a production and return network for refrigerators," Erasmus Research Institute of Management, vol. 17, no. 8, pp. 312-319, 2001.

[2] V. Jayaraman, V. D. R. Guide Jr., and J. D. Linton, "Building contingency planning for closed-loop supply chains with product recovery," Journal of Operations Management, vol. 21, no. 3, pp. 259-279, 2003.

[3] R. C. Savaskan, S. Bhattacharya, and L. Van Wassenhove, "Closed-loop supply chain models with product remanufacturing," Management Science, vol. 50, no. 2, pp. 239-252, 2004.

[4] J. Forrester, Industrial Dynamics, MIT Press, Cambridge, UK, 1961.

[5] J. D. Sterman, "Modeling managerial behavior: misperceptions of feedback in a dynamic decision making experiment," Management Science, vol. 35, no. 3, pp. 321-339, 1989.

[6] Y. Baik, Control in the Extended Enterprise, University of Waterloo, Ontario, Canada, 1997.

[7] X. L. Liu, J. H. Ji, and J. L. Li, "The network structure in the supply chain based on the system dynamics simulation," System Engineer, vol. 24, no. 6, pp. 40-45, 2006.

[8] F. Chen, Z. Drezner, J. K. Ryan, and D. Simchi-Levi, "Quantifying the bullwhip effect in a simple supply chain: the impact of 
forecasting, lead times, and information," Management Science, vol. 46, no. 3, pp. 436-443, 2000.

[9] F. Chen, J. K. Ryan, and D. Simchi-Levi, "The impact of exponential smoothing forecasts on the bullwhip effect," Naval Research Logistics, vol. 47, no. 4, pp. 269-286, 2000.

[10] H.-K. Kim and J. K. Ryan, "The cost impact of using simple forecasting techniques in a supply chain," Naval Research Logistics, vol. 50, no. 5, pp. 388-411, 2003.

[11] G. Gaalman and S. M. Disney, "State space investigation of the bullwhip problem with ARMA $(1,1)$ demand processes," International Journal of Production Economics, vol. 104, no. 2, pp. 327-339, 2006.

[12] D. C. Chatfield, J. G. Kim, T. P. Harrison, and J. C. Hayya, “The bullwhip effect-impact of stochastic lead time, information quality, and information sharing: a simulation study," Production and Operations Management, vol. 13, no. 4, pp. 340-353, 2004.

[13] T. Hosoda and S. M. Disney, "On variance amplification in a three-echelon supply chain with minimum mean square error forecasting," Omega, vol. 34, no. 4, pp. 344-358, 2006.

[14] S. Cannella and E. Ciancimino, "On the bullwhip avoidance phase: supply chain collaboration and order smoothing," International Journal of Production Research, vol. 48, no. 22, pp. 6739-6776, 2010.

[15] C. B. Lehr, J.-H. Thun, and P. M. Milling, "From waste to valuea system dynamics model for strategic decision-making in closed-loop supply chains," International Journal of Production Research, vol. 51, no. 13, pp. 4105-4116, 2013.

[16] Y. Savaskan, Y. Abhishak, and K. Narendra, "The bullwhip effect-impact of lead time, information quality, and information sharing," International Journal of Engineering and Technical Research, vol. 1, no. 9, pp. 90-93, 2013.

[17] G. Ferrer and J. M. Swaminathan, "Managing new and differentiated remanufactured products," European Journal of Operational Research, vol. 203, no. 2, pp. 370-379, 2010.

[18] P. Georgiadis and M. Besiou, "Environmental and economical sustainability of WEEE closed-loop supply chains with recycling: a system dynamics analysis," International Journal of Advanced Manufacturing Technology, vol. 47, no. 5-8, pp. 475493, 2010.

[19] D. S. Rogers, Z. S. Rogers, and R. Lembke, "Creating value through product stewardship and take-back," Sustainability Accounting, Management and Policy Journal, vol. 1, no. 2, pp. 133-160, 2010.

[20] J. Wei and J. Zhao, "Pricing decisions with retail competition in a fuzzy closed-loop supply chain," Expert Systems with Applications, vol. 38, no. 9, pp. 11209-11216, 2011.

[21] D. Das and P. Dutta, "A system dynamics framework for an integrated forward-reverse supply chain with fuzzy demand and fuzzy collection rate under possibility constraints," in Proceedings of the International Multi-Conference of Engineers and Computer Scientists (IMECS '12), vol. 55, pp. 1592-1597, Hong Kong, March 2012. 


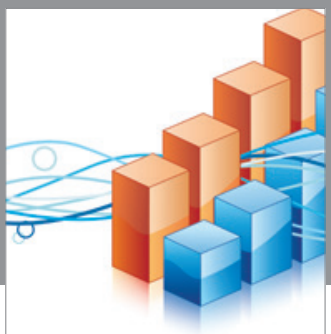

Advances in

Operations Research

vatem alat4

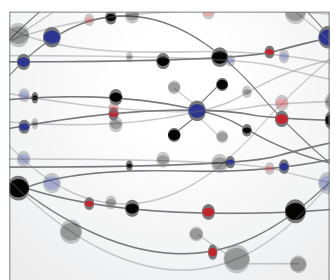

\section{The Scientific} World Journal
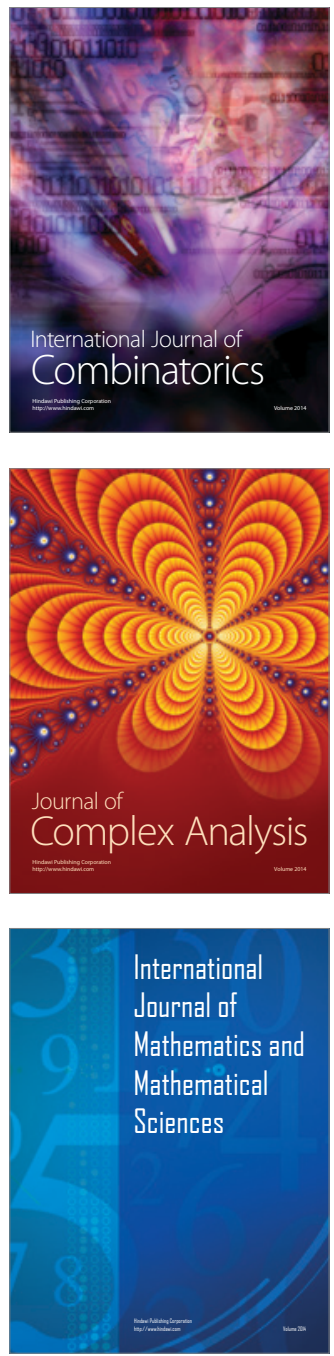
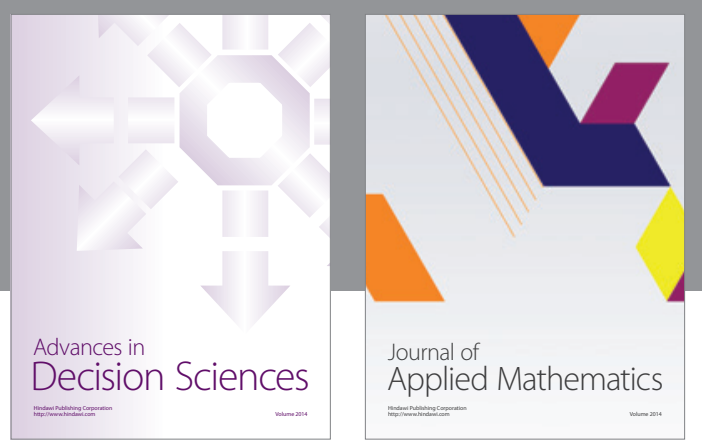

Algebra

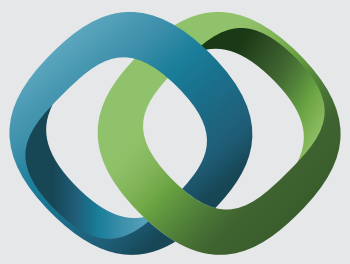

\section{Hindawi}

Submit your manuscripts at

http://www.hindawi.com
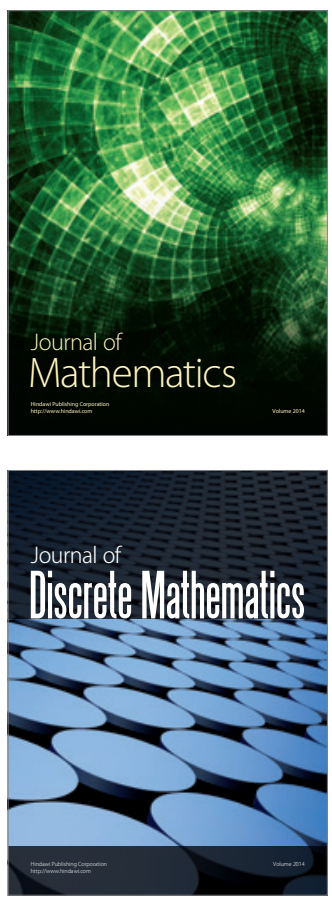

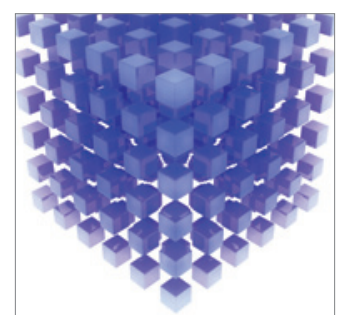

Mathematical Problems in Engineering
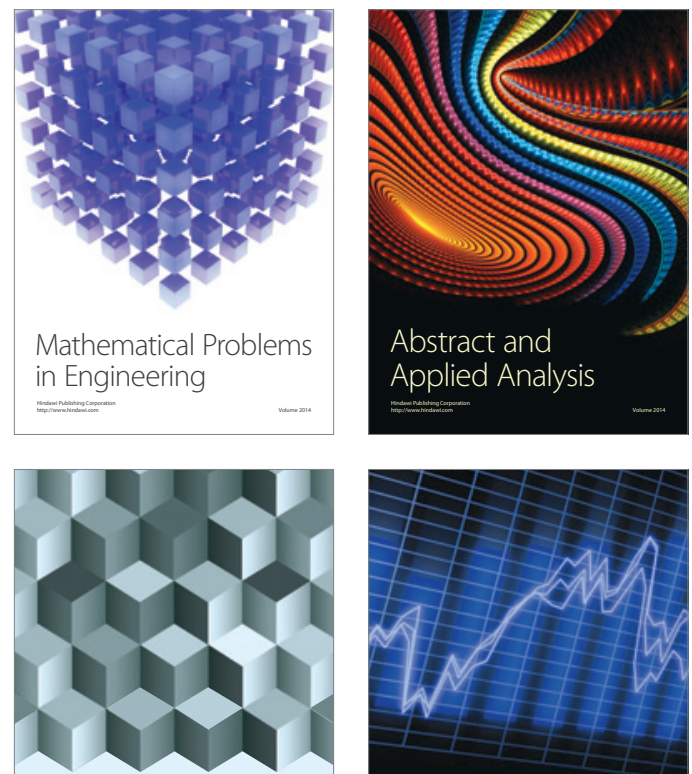

Journal of

Function Spaces

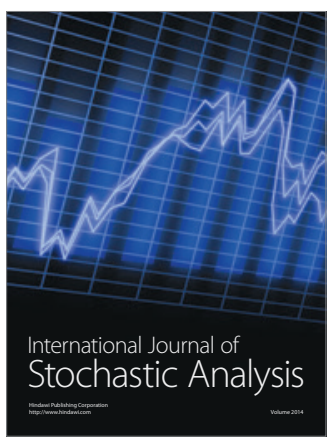

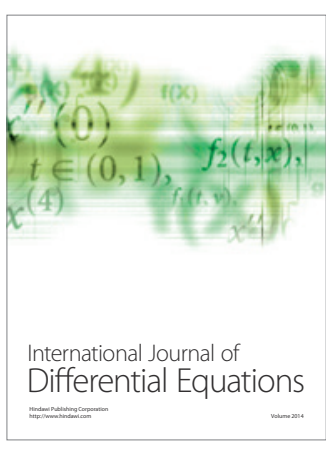
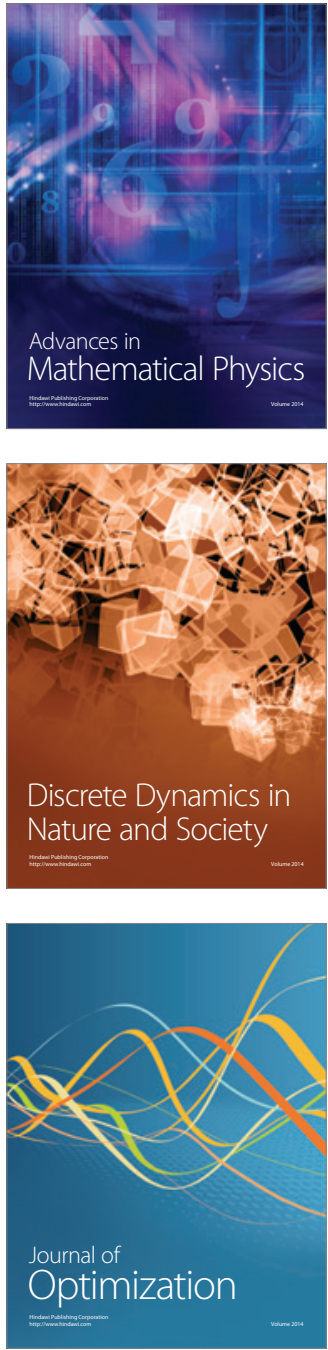